SHORT REPORT

\title{
Are functional motor and sensory symptoms really more frequent on the left? A systematic review
}

\author{
J Stone, M Sharpe, A Carson, S C Lewis, B Thomas, R Goldbeck, C P Warlow
}

J Neurol Neurosurg Psychiatry 2002;73:578-581

Objectives: To test the hypothesis that unilateral motor and sensory symptoms unexplained by identifiable disease are more common on the left side of the body than the right. Methods: Systematic review of the literature published since 1965.

Results: 121 eligible studies, involving 1139 patients, were analysed. The pooled proportion of functional left sided weakness and sensory symptoms in adults was $58 \%$ (95\% confidence interval (CI) 55 to $61 \%$ ). A much higher proportion of left sided symptoms $166 \%, 95 \% \mathrm{Cl} 61$ to $71 \%$ ) was found in studies where laterality featured in the title of the paper. However, when laterality was not mentioned in the title, no significant difference between left and right was observed $153 \%$ on the left, $95 \% \mathrm{Cl} 48$ to $57 \%$ ). This difference could not be explained on the basis of sex differences between the groups or the date of the study. Functional or "psychogenic" movement disorder was right sided in $68 \%(95 \% \mathrm{Cl} 61$ to $75 \%)$. Handedness did not influence symptom lateralisation.

Conclusions: The findings of this systematic review question whether functional weakness and sensory symptoms do in fact occur more commonly on the left side of the body. A type of outcome variable reporting bias in combination with non-blinding of investigators may be responsible for this long held but erroneous belief.

S ymptoms unexplained by identifiable disease (medically unexplained symptoms), sometimes called "functional", "psychogenic", or "hysterical", account for up to one third of new neurological outpatients and are poorly understood. ${ }^{1}$ Functional motor and sensory symptoms such as weakness, tremor, and numbness are often unilateral and are said to be more common on the left side of the body than the right. ${ }^{2}$

This apparent asymmetry of symptoms has led to much speculation. Is this left sided preponderance due to functional asymmetry of emotional processing favouring the right hemisphere $?^{45}$ Are there parallels between "la belle indifference", said to accompany hysteria in some cases, and parietal anosagnosia, usually a right hemisphere problem? Is it simply less disabling to have a malfunctioning non-dominant limbthe so called "convenience hypothesis"?

These theories-linking neurobiology with clinical practice-are attractive, but are they based on a valid assumption? We undertook a systematic review of the published literature since 1965 to examine whether it supports the hypothesis that functional neurological symptoms are more common on the left side of the body and to explore possible biases in previous studies.

\section{METHODS}

\section{Search strategy}

We searched the following databases: Medline (from 1966), Cinahl (from 1982), Embase (from 1980) and Psyclit (from
1965) to June 2001. We used all database controlled vocabulary headings for functional neurological symptoms in addition to the following text words: psychosomatic, psychogenic, somatisation, unexplained, conversion, non-organic, dissoc*. These were combined with headings and text words for paralysis, paresis, sensory disturbance, hyperventilation, movement disorders, laterality, and cerebral dominance. In addition, we examined all references under the heading "conversion disorder" or with the text word hysteri*. We reviewed the titles and abstracts on line and obtained copies of all studies that conceivably contained data on laterality. The reference lists of all obtained articles were hand searched for further articles published after 1965. Studies in English, French, Spanish, and German were included.

\section{Study inclusion and exclusion}

Studies were included if the following criteria were met: firstly, they reported at least one patient with symptoms described as medically unexplained, functional, non-organic, psychogenic, hysterical, conversion disorder, or hyperventilation; and secondly, data on the laterality of a motor symptom (weakness or movement disorder (dystonia, tremor, or myoclonus) of face, arm, or leg) or sensory symptom (face, arm, trunk, and leg) could be extracted. We included studies of functional motor or sensory symptoms associated with pain but excluded studies where unexplained pain was the sole symptom. We also excluded studies of functional visual or hearing loss and those reporting motor symptoms as part of reflex sympathetic dystrophy or complex regional pain type 1 .

We hypothesised that "headline" studies, in which the title referred to laterality or location of the symptom, would be more likely to have found a left sided predominance than "non-headline" studies, in which laterality was recorded incidentally. In addition, we conducted exploratory analyses to examine the influence of sex, date of study, and handedness on symptom laterality.

\section{Data extraction and analysis}

Three investigators reviewed the papers independently (JS, RG, and AC) using a structured proforma. Two adjudicators (MS and CPW) resolved discrepancies. We collected the following data: (a) the nature of the symptom: sensory, weakness, or movement disorder; (b) whether the title referred to the laterality or location of the symptoms (headline studies); (c) sex, (d) year of publication, and (e) handedness. If a patient was recorded as having ipsilateral weakness and sensory disturbance this was counted as a motor symptom and then again as a sensory symptom but only once for the combined analyses.

Three methods of meta-analysis were used. Firstly, we obtained a simple pooled average by adding data summatively

Abbreviations: $\mathrm{Cl}$, confidence interval 


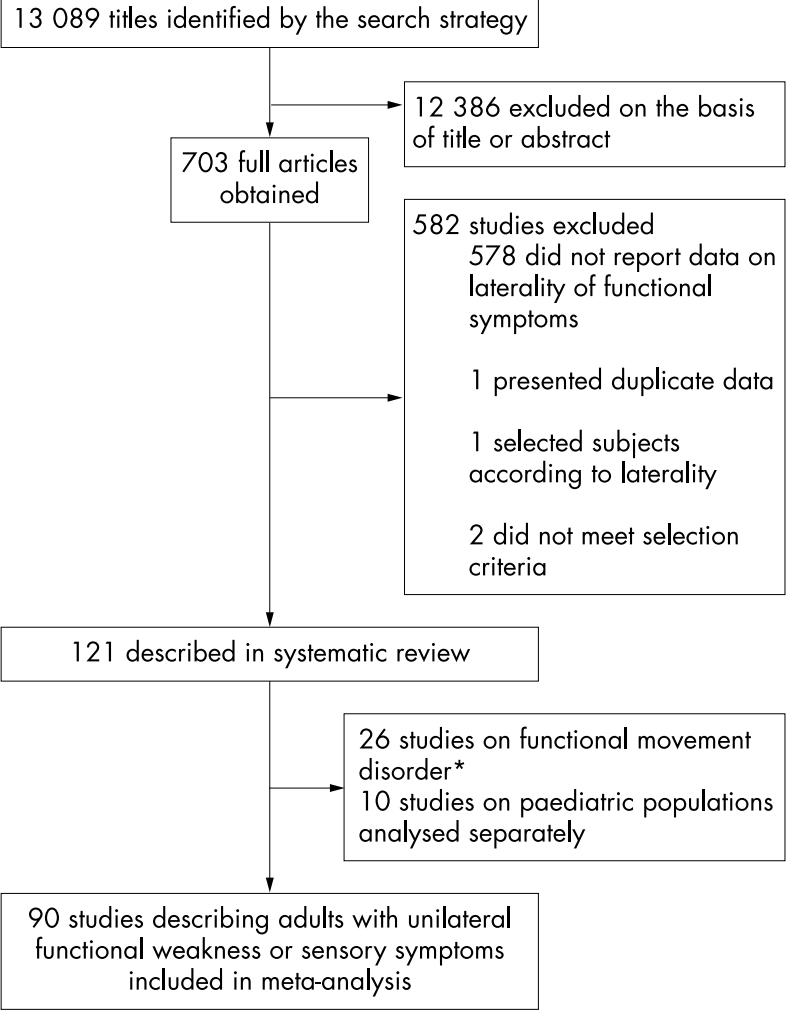

Figure 1 Selection of reports. *Five studies presented data on both movement disorder and weakness - in these cases the data were split.

so that each study contributed to the final result according to its size. Secondly, we used a fixed effects model, which assumes that all studies are measuring an outcome that is constant across different populations. Studies with fewer than 20 subjects were aggregated to make a single additional data point for this analysis. Thirdly, we applied, in a similar way, a random effects model that assumed that the studies were a random sample representative of all hypothetically available results.

\section{RESULTS}

\section{Searching}

Figure 1 shows the number of studies we included and excluded, with reasons for exclusion. We reviewed 13089 titles and abstracts and obtained 703 papers. Of these, 121 studies met the study entry criteria and comprised observations on 1139 patients.

Only four studies that reported laterality of motor and sensory symptoms were excluded. Stefansson et $a l^{6}$ commented on 31 mainly right sided conversion symptoms but many had "conversion pain". Another study cited duplicate data ${ }^{7}$ and in an additional study it was not clear which side the symptoms were on. ${ }^{8}$ A final study had initially looked for patients with symptoms on the same side for imaging purposes (although left and right were represented in the final study). ${ }^{9}$

Four studies ${ }^{10-13}$ of patients with conversion symptoms that included unilateral deafness and blindness were included because at least $80 \%$ of the data related to weakness or sensory disturbance. Ninety studies were of weakness and sensory disturbance in adults. There were 12 studies in which the title referred either to laterality ${ }^{14-24}$ or location of the symptoms ${ }^{10}$ and 78 "non-headline" studies. ${ }^{\text {wl-w78 }}$

There were 26 studies of laterality of functional movement disorder. ${ }^{\text {w7 }}$ w15 ${ }^{\text {w43 }}$ w79-w101 Five studies contained data on both patients with weakness and patients with movement disor$\operatorname{der}^{\mathrm{w} 7 \mathrm{w} 15 \mathrm{w} 43 \mathrm{w} 92 \mathrm{w} 96}$ and in these the data were split accordingly. In

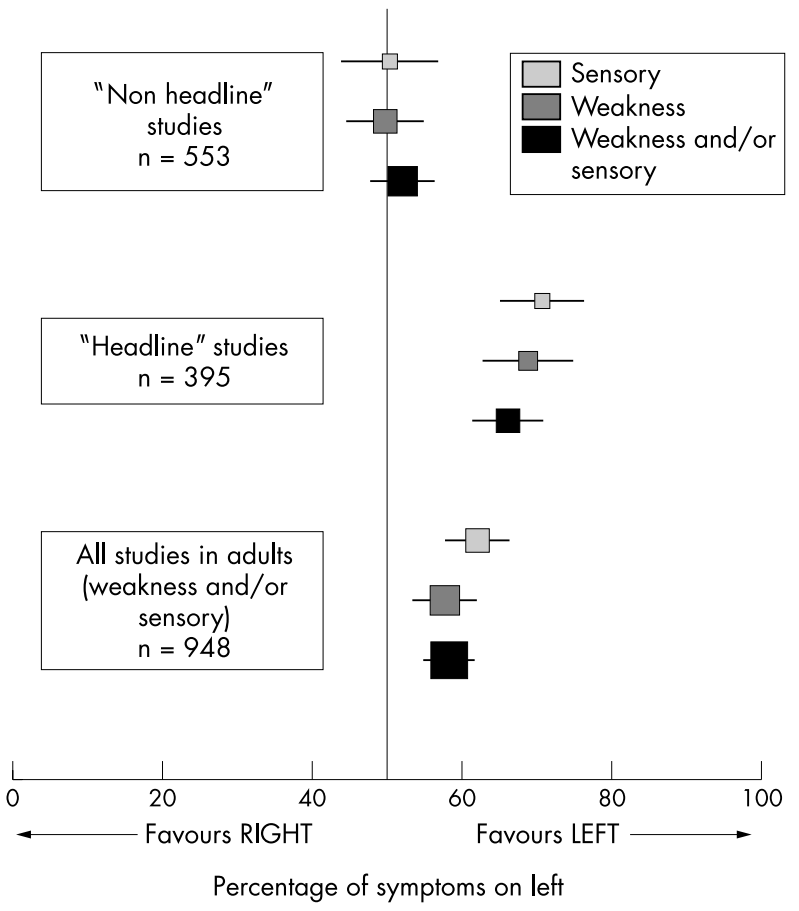

Figure 2 Laterality of functional weakness and sensory symptoms in adults according to whether laterality featured in the title of the paper. Size of square is relative to number of patients in analysis. Lines represent $95 \%$ confidence interval. $n$, number of patients in each meta-analysis. Values are based on simple pooling technique.

the 10 paediatric studies we found, only 28 subjects with lateralised symptoms were available for analysis. ${ }^{\mathrm{w} 102-\mathrm{w} 111}$

\section{Analysis}

Figure 2 and table 1 show the results of the meta-analysis based on the simple pooled values. When all studies of adults were included, $58 \%$ of patients had functional weakness, sensory symptoms, or both on the left side of the body (95\% confidence interval (CI) 55 to $61 \%$ ). However, the analysis by type of study was revealing. In the non-headline studies, only $53 \%$ ( $95 \%$ CI 48 to $57 \%$ ) of symptoms occurred on the left. This is in contrast to headline studies where $66 \%$ (95\% CI 61 to $71 \%$ ) had functional symptoms on the left. The fixed and random effects models, apart from the expected wider CIs in the random effects model, produced broadly the same overall result as did simple pooling of data (table 1).

To determine whether the way we had coded sensory symptoms had affected the result, we reanalysed the data, counting sensory symptoms only if they were unaccompanied by motor symptoms. The results were similar-in particular the CIs for sensory symptoms in the non-headline group continued to cross the $50 \%$ line.

We analysed the relation of sex to laterality of adult functional weakness or sensory symptoms where individual patient data were available ( $55 \%$ of cases). Female patients had significantly more left sided symptoms $(66 \%)$ than male patients $(56 \%$; Fisher's exact test $\mathrm{p}<0.05)$ but this did not account for the difference between headline and non-headline studies. An analysis of studies by year of publication did not show any trend since 1965, suggesting no influence of the availability of modern investigations such as magnetic resonance imaging.

We also explored the effects of handedness. A pooled analysis of all nine studies in adults with weakness and sensory symptoms and handedness data ${ }^{\mathrm{w} 7}$ w19 w29 w72 w74 w96 w112-w114 that $55 \%$ (95\% CI 39 to $71 \%$ ) of left handed patients had left sided symptoms $(n=38)$, suggesting that this is not a major 
Table 1 Meta-analysis of proportion of left sided functional motor and sensory symptoms

\begin{tabular}{|c|c|c|c|c|c|}
\hline & \multirow[b]{2}{*}{$\begin{array}{l}\text { Number } \\
\text { of studies }\end{array}$} & \multirow[b]{2}{*}{$\begin{array}{l}\text { Number } \\
\text { of patients }\end{array}$} & \multicolumn{3}{|c|}{ Left sided symptoms (\%) } \\
\hline & & & $\begin{array}{l}\text { Simple pooled } \\
\text { values* } \\
(95 \% \mathrm{Cl})\end{array}$ & $\begin{array}{l}\text { Fixed effects } \\
\text { model } \dagger \\
(95 \% \mathrm{Cl})\end{array}$ & $\begin{array}{l}\text { Random effects } \\
\text { model } \dagger \\
(95 \% \mathrm{Cl})\end{array}$ \\
\hline \multicolumn{6}{|c|}{$\begin{array}{l}\text { Adults - weakness or sensory disturbance } \\
\text { All studies }\end{array}$} \\
\hline Sensory & 42 & 501 & 62 (58 to 66$)$ & 65 (61 to 69) & 69 (59 to 80$)$ \\
\hline Weakness & 82 & 584 & $58(54$ to 62$)$ & $59(56$ to 63$)$ & $64(55$ to 73$)$ \\
\hline $\begin{array}{l}\text { Sensory and/or weakness } \\
\text { Headline studies }\end{array}$ & 90 & 948 & $58(55$ to 61$)$ & 60 (57 to 63$)$ & 61 (53 to 68) \\
\hline Sensory & 8 & 281 & $70(65$ to 76$)$ & 72 (67 to 77$)$ & 77 (69 to 84$)$ \\
\hline Weakness & 10 & 230 & 69 (63 to 75) & 70 (64 to 76$)$ & 71 (63 to 78$)$ \\
\hline $\begin{array}{l}\text { Sensory and/or weakness } \\
\text { Non-headline studies }\end{array}$ & 12 & 395 & 66 (61 to 71$)$ & 67 (62 to 71$)$ & 65 (54 to 76$)$ \\
\hline Sensory $\ddagger$ & 34 & 220 & 51 (44 to 58$)$ & & \\
\hline Weakness $\ddagger$ & 72 & 354 & $50(45$ to 55$)$ & & \\
\hline Sensory and/or weakness & 78 & 553 & 53 (48 to 57$)$ & 54 (50 to 58$)$ & 56 (48 to 65$)$ \\
\hline Left handed $\ddagger$ & 9 & 38 & 55 (39 to 71$)$ & & \\
\hline Male & 78 & 167 & 56 (48 to 63$)$ & & \\
\hline Femalef & 78 & 358 & $66(61$ to 70$)$ & & \\
\hline Movement disorder $\ddagger$ & 26 & 163 & 32 (25 to 39$)$ & & \\
\hline Paediatric population $\ddagger$ & 10 & 28 & $48(30$ to 66$)$ & & \\
\hline
\end{tabular}

*Values from individual studies were added together so that each study weights itself. †Fixed and random effects modelling of all studies where $n>20$ and other studies amalgamated as a single data point. łlnsufficient studies with $\mathrm{n}>20$ to allow meaningful fixed and random analysis.

determinant. The proportion of left handers overall was slightly above that in the general population at 16\% (95\% CI 11 to $21 \%$ ).

Functional or "psychogenic" movement disorder (tremor, dystonia, myoclonus) occurred on the right side in $68 \%$ (95\% CI 61 to $75 \%$ ). In the paediatric group $48 \%$ of symptoms were on the left but with wide CIs because there were only 28 subjects (95\% CI 30 to $66 \%$ ).

\section{DISCUSSION}

\section{Left sided functional symptoms may not be more} common than right

These findings cast doubt on the hypothesis that functional weakness and sensory symptoms are more common on the left than the right. Although the overall pooled result suggests a slight left lateralising effect, this may not be the most accurate answer to the question. We suggest that, for a variable as obvious as laterality, studies in which the investigators are blind to the hypothesis are preferable. It is likely that blinding was more common in the non-headline group. In this group there was no clear lateralising effect.

\section{Limitations}

One source of heterogeneity in this sample may be that functional symptoms arising "spontaneously", as might be seen in hyperventilation, may be more left sided, whereas symptoms following on from pain, for example, after a work related injury, may be more right sided..$^{20}$ There are insufficient data to answer this question. Another limitation is that some studies may have included patients with misdiagnosed "hysteria" who in fact had organic disease. Misdiagnosis is now unusual $^{25}$ (a recent London study found a misdiagnosis rate of $5 \%$ at six years ${ }^{25}$ ) and the lack of trend by date of study is also reassuring in this respect.

\section{Research implications: "buried" negative results may differ from "headline" positive results}

The "headline bias" we propose may be described as a case of "when you're looking for a positive result you're more likely to find it". This bias emphasises the danger in carrying out research without blinding, particularly when there may be a strong preconception of the result. We found that data contrary to the prevalent hypothesis were more likely to be buried in the paper than headlined in the title. This can be described as outcome variable reporting bias. ${ }^{26}$ While it is difficult in observational studies to eliminate bias and to blind investigators, the recording of data incidentally by investigators interested in another outcome may be the best way of achieving it.

\section{Clinical and theoretical implications: laterality is not a useful clinical sign}

The clinical implications of our study are that the laterality of a patient's symptoms should not be used to judge whether symptoms are likely to be associated with recognisable neurological disease. Similar caution is urged before theorising on the assumption that such symptoms are more common on the left.

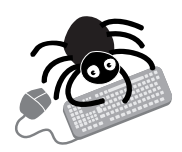

Additional references appear on the JNNP website (www.jnnp.com)

\section{Authors' affiliations}

J Stone, A Carson, S C Lewis, B Thomas, C P Warlow, Department of Clinical Neurosciences, University of Edinburgh, Western General Hospital, Crewe Road, Edinburgh EH4 2XU, UK

M Sharpe, Department of Psychiatry, University of Edinburgh, Royal Edinburgh Hospital, Morningside Park, Edinburgh, EH10 5HF, UK R Goldbeck, Department of Psychological Medicine 3rd floor, Phase II, Aberdeen Royal Infirmary, Aberdeen AB25 2ZN, UK

Competing interest: None of the authors is left handed

Correspondence to: Dr J Stone, Department of Clinical Neurosciences, Western General Hospital, Edinburgh EH4 2XU, UK; jstone@skull.dcn.ed.ac.uk

Received 2 April 2002

In revised form 4 July 2002

Accepted 24 July 2002

\section{REFERENCES}

1 Carson AJ, Ringbauer B, Stone J, et al. Do medically unexplained symptoms matter? A prospective cohort study of 300 new referrals to 
neurology outpatient clinics. J Neurol Neurosurg Psychiatry 2000;68:207-10.

2 Putnam FW. Conversion symptoms. In: Joseph AB, Young RR, eds. Movement disorders in neurology and neuropsychiatry. Oxford: Blackwell Scientific, 1998.

3 Trimble MR. Behavior and personality changes. In: Bradley WG, Daroff $\mathrm{RB}$, Fenichel GM, et al, eds. Neurology in clinical practice. Boston: Butterworth Heinemann, 2000:101.

4 Galin D. Lateral specialization and psychiatric issues: speculations on development and the evolution of consciousness. Ann NY Acad Sci 1977:299:397-411.

5 Merskey H, Watson GD. The lateralisation of pain. Pain 1979;7:271-80.

6 Stefansson JG, Messina JA, Meyerowitz S. Hysterical neurosis, conversion type: clinical and epidemiological considerations. Acta Psychiatr Scand 1976;53:119-38.

7 Levy R, Behrman J. Cortical evoked responses in hysterical hemianaesthesia. Electroencephalogr Clin Neurophysiol 1970;29:400-2.

8 Sharma P, Chaturvedi SK. Conversion disorder revisited. Acta Psychiatr Scand 1995;92:301-4

9 Spence SA, Crimlisk HL, Cope H, et al. Discrete neurophysiological correlates in prefrontal cortex during hysterical and feigned disorder of movement. Lancet 2000;355:1243-4.

10 Fallik A, Sigal M. Hysteria: the choice of symptom site. Psychother Psychosom 1971;19:310-8.

11 Kapfhammer HP, Buchheim P, Bove D, et al. Konversionssymptome be Patienten im psychiatrischen Konsiliardienst. Nervenarzt 1992;63:527-38.

12 Lecompte D, Clara A. Associated psychopathology in conversion patients without organic disease. Acta Psychiatr Belg 1987;87:654-61.

13 Folks DG, Ford CV, Regan WM. Conversion symptoms in a general hospital. Psychosomatics 1984;25:285-9, 291, 294-5.
14 Galin D, Diamond R, Braff D. Lateralization of conversion symptoms: more frequent on the left. Am J Psychiatry 1977;134:578-80.

15 Stern DB. Handedness and the lateral distribution of conversion reactions. J Nerv Ment Dis 1977;164:122-8.

16 Bishop ER Jr, Mobley MC, Farr WF Jr. Lateralization of conversion symptoms. Compr Psychiatry 1978;19:393-6.

17 Fleminger JJ, McClure GM, Dalton R. Lateral response to suggestion in relation to handedness and the side of psychogenic symptoms. $\mathrm{Br} \mathrm{J}$ Psychiatry 1980;136:562-6.

18 Krueger DW. Unilateral ptosis as a conversion reaction. J Clin Psychiatry 1978;39:351-6.

19 O'Sullivan G, Harvey I, Bass C, et al. Psychophysiological investigations of patients with unilateral symptoms in the hyperventilation syndrome. $\mathrm{Br} J$ Psychiatry 1992;160:664-7.

20 Rothwell P. Investigation of unilateral sensory or motor symptoms: frequency of neurological pathology depends on side of symptoms. $J$ Neurol Neurosurg Psychiatry 1994:57:1401-2.

21 Pascuzzi RM. Nonphysiological (functional) unilateral motor and sensory syndromes involve the left more often than the right body. J Nerv Ment Dis 1994; 182:118-20.

22 Min SK, Lee BO. Laterality in somatization. Psychosom Med 1997:59:236-40.

23 Roelofs K, Naring GW, Moene FC, et al. The question of symptom lateralization in conversion disorder. J Psychosom Res 2000;49:21-5.

24 Blau JN, Wiles CM, Solomon FS. Unilateral somatic symptoms due to hyperventilation. BM 1983;286:1108

25 Crimlisk HL, Bhatia K, Cope H, et al. Slater revisited: 6 year follow up study of patients with medically unexplained motor symptoms. BM 1998;316:582-6.

26 Hahn S, Williamson PR, Hutton JL, et al. Assessing the potential for bias in meta-analysis due to selective reporting of subgroup analyses within studies. Stat Med 2000;19:3325-36.

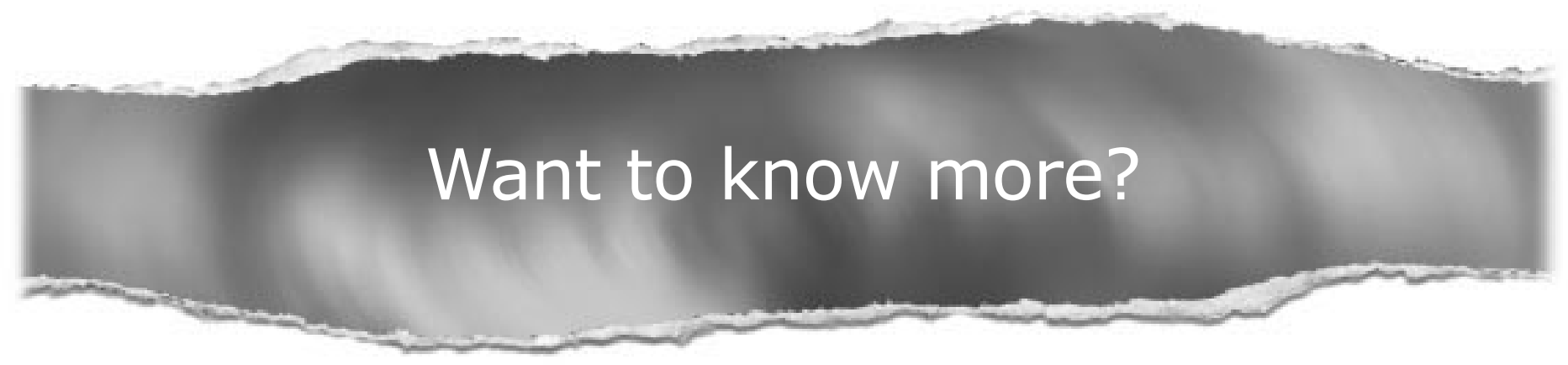

\section{Data supplements}

Limited space in printed journals means that interesting data and other material are often edited out of articles; however, limitless cyberspace means that we can include this information online.

Look out for additional tables, references, illustrations.

\section{www.jnnp.com}

